\title{
Chapter 3 \\ Socio-demographic Risk Factors Related to Material Deprivation Among Older \\ Persons in Europe: A Comparative Analysis Based on SHARE Data
}

\author{
Merle Sumil-Laanemaa, Luule Sakkeus, Allan Puur, and Lauri Leppik
}

\subsection{Introduction}

The concept of social exclusion encompasses the processes and interplay of factors that hinder personal well-being and, consequently, full and equal participation in society. The ageing of the population warrants research on social exclusion in older age, examining the processes and risk factors of exclusion that can predominate in later life (Walsh et al. 2017). Scharf et al. (2005) conceptualise social exclusion in old-age as a phenomenon with five dimensions: material resources, social relations, civic activities, basic services, and neighbourhoods. Myck et al. (2017) point out that economic exclusion in later life - a process that relates to the focus of this chapter - is rooted in the development of material well-being over the life course and entails an incapacity to address expected and unexpected changes in the level of material conditions and needs. In addition to current income, economic exclusion involves low assets, a shortage of durable goods accumulated over the life course, limited access to services, and other types of non-monetary material wealth. The concept of material deprivation also includes non-monetary aspects of economic exclusion (Boarini and Mira d'Ercole 2006).

Only few studies to date have explored the individual risk factors of material deprivation (such as sex, age, education, household size and socio-economic status) among older persons from a broad cross-national comparative perspective (e.g. Jehoel-Gijsbers and Vrooman 2008). Lacking an understanding of how the influence of these factors might vary across different jurisdictions and different types of welfare regimes not only impacts negatively on scholarly knowledge but on our capacity for meaningful pan-European policy development. In this study, we aim to identify differences in material deprivation among older persons in Europe, analyse

M. Sumil-Laanemaa $(\bowtie) \cdot$ L. Sakkeus $\cdot$ A. Puur $\cdot$ L. Leppik

Estonian Institute for Population Studies, School of Governance, Law and Society,

Tallinn University, Tallinn, Estonia

e-mail: merle.sumil-laanemaa@tlu.ee 
the associations between socio-demographic risk factors and material deprivation, and the ways in which these associations differ across welfare regimes. The analysis provides further insights into the individual components of material deprivation and the complexity of the disadvantages experienced by older persons (Saunders 2008; Scharf 2015).

\subsection{Material Deprivation: Operationalisation and Risk Factors}

\subsubsection{Concept and Operationalisation}

Fusco et al. (2010) define material deprivation as an inability to possess the goods and services and/or engage in activities that are customary in society, or that are socially perceived as "necessities". The concept of material deprivation thus addresses aspects of economic exclusion that are not covered by current income, such as effective economic hardship and limited access to basic goods and services (Renahy et al. 2012). Myck et al. (2017) suggest that measures of material deprivation have several important advantages over traditional income-based and subjective measures of material well-being and exclusion. They refer directly to failures in effective capacity, while measuring material conditions more objectively than a subjective self-assessment of one's overall material situation, and are consequently more comparable across population groups and between countries. However, Myck et al. also note that measures of material deprivation are somewhat arbitrary in terms of their construction and composition, given that needs, expectations and preferences vary across subgroups of the population and may change over time.

The operational definitions of material deprivation vary according to the items that are included in the "basket" of basic goods and services considered ordinary or necessary, and the weights assigned to them (Guio 2009). These choices thus have a normative element.

The EU portfolio of social inclusion indicators defines the material deprivation rate (MDR) and severe material deprivation rate (SMDR) as the proportion of the population living in households that are unable to afford at least three (for the MDR) or four (for the SMDR) of the following nine items: (1) to pay rent or utility bills; (2) to keep their home adequately warm; (3) to meet unexpected expenses; (4) to eat meat, fish or a protein equivalent every second day; (5) to take a week's holiday away from home; or could not afford if they wanted to have: (6) a car; (7) a washing machine; (8) a colour television; or (9) a telephone. Although the total household is taken into account, the unit of analysis for the EU indicators is the individual within his/her household (Fusco et al. 2010). The MDR and SMDR are calculated based on EU-SILC (EU Statistics on Income and Living Conditions) data (Eurostat 2019). Fusco et al. (2013) comment that such indicators aggregate information on some key aspects of material living conditions, but do not cover all dimensions of 
economic exclusion. The selection of items in the aggregate indicator is based on a lack of affordability rather than on personal choice or lifestyle preferences.

An alternative measure - the Material Deprivation Index (MDI) - has been developed within the framework of the Survey of Health, Ageing and Retirement in Europe (SHARE). The composition have this assessment of material deprivation bears some similarities to the Eurostat indicators, but there are also differences. The MDI is based on a set of 11 material deprivation indicators that refer to a household's financial difficulties and inability to meet basic needs (Adena et al. 2015).

Basic needs include the ability to: (1) have meat, fish or chicken; and (2) fruits or vegetables, in the household diet at least three times a week; (3) purchase necessary groceries and household supplies; (4) pay for adequate heating; (5) replace wornout shoes; and (6) clothes; (7) purchase new glasses when needed; and (8) see a doctor; and (9) dentist. Indicators of financial difficulties include the inability to afford: (10) a week-long holiday; and (11) to pay unexpected expenses without borrowing. Compared with the EU-SILC-based material deprivation indicators, SHARE's MDI does not include possession of or ability to afford durable goods such as a car, washing machine, or colour television. Instead, the MDI focusses more on immediate basic needs, such as the affordability of fruits and vegetables, shoes and clothes, and seeing a doctor or dentist. It is argued that this approach makes the MDI more suitable for measuring material deprivation among older persons (Adena et al. 2015).

\subsubsection{Risk Factors Related to Material Deprivation}

A considerable number of earlier studies have analysed the links between material deprivation and socio-demographic risk factors such as sex, age, education, household size and socio-economic status. Several studies have found higher rates of material deprivation among women, although the material deprivation gender gap remains largely unexplained (Bárcena-Martín et al. 2014). Numerous studies have examined the connection between material deprivation and age, with somewhat contradictory results. Jehoel-Gijsbers and Vrooman (2008) and Dewilde (2008) observed that in almost all European countries material deprivation decreases with age. This is explained by the large proportion of older persons who own their home, which allows them to manage on a smaller income (Dewilde 2008); furthermore, the author posits that older people have better budgeting skills or grew up in an era when people had fewer material desires. In contrast, Hrast et al. (2013) showed that older people in Central and Eastern Europe experience significantly higher levels of exclusion than the rest of the population, identifying material deprivation as one of the biggest problems, and pointing to the failure of post-socialist welfare states to promote social inclusion among older people.

Several studies have established that less well-educated persons face a greater risk of material deprivation, whereas higher levels of education reduce the risk (Bárcena-Martín et al. 2014; Saltkjel and Malmberg-Heimonen 2017). The link 
between socio-economic status and the risk of material deprivation has also been well established. Unemployed or inactive persons have a higher risk [see Murdock et al. this section for an analysis of the impact of unemployment in later life], while households with one or more employed workers exhibit lower deprivation scores (De Graaf-Zijl and Nolan 2011; Bárcena-Martín et al. 2014).

Regarding the relationship between material deprivation and the structure of the household, studies have revealed fairly similar results across European countries. Those living alone, single parents, and families with small children are especially vulnerable (Boarini and Mira d'Ercole 2006; Dewilde 2008). From a life-course perspective, those in later life are particularly susceptible to specific events that affect the composition of the household. Adult children leaving home, divorce, or the death of a spouse [see Barlin et al. this section for a discussion of the material circumstances of widowed, and separated and divorced older women] may increase the risk of material deprivation (Bárcena-Martín et al. 2014).

A number of other key risk factors have also been identified. Franzese (2015), for example, has shown that material deprivation is strongly correlated with both physical and mental health. According to Hunkler et al. (2015), migrants experience greater material deprivation in older-age than non-migrants [see Gallassi and Harrysson this volume for a discussion of the economic and social situation of older migrants]. Levasseur et al. (2015) observed that despite higher residential density and social deprivation in urban areas with larger populations, material deprivation was greater among older adults in rural areas.

Several studies have attempted to ascertain the capacity of welfare states to modulate the risk of material deprivation (Muffels and Fouarge 2004; Jehoel-Gijsbers and Vrooman 2008; Nelson 2012; Saltkjel and Malmberg-Heimonen 2017). Muffels and Fouarge (2004) analysed 11 European countries and observed a higher prevalence of material deprivation in Southern and Liberal welfare regimes compared with Corporatist and Social-democratic regimes, concluding that the practices of welfare regimes concerning the distribution of resources and opportunities do have an effect on differences in material deprivation across countries. Jehoel-Gijsbers and Vrooman (2008) examined material deprivation among older people (aged 55 and over) in 26 European countries and observed the highest rates of material deprivation in Eastern Europe, followed by the Mediterranean welfare cluster. Nelson (2012) found the rate of material deprivation to be lower in countries with higher levels of social benefits. Similarly, Saltkjel and Malmberg-Heimonen (2017) demonstrated that the generous benefits of welfare states moderated the risk of material deprivation. However, it should be noted that, while Jehoel-Gijsbers and Vrooman (2008) focused on the 55+ age group, all of these other studies concentrate on those aged between 18-64 years. Consequently, how these risk factors vary across welfare regimes in later life remains poorly understood.

In summary, despite the sizeable number of studies investigating the links between material deprivation and socio-demographic risk factors and their variation across European countries, most existing studies do not focus specifically on older persons, are based on the EU material deprivation rate, and sometimes include only 
a limited set of individual risk factors. These gaps in existing research provided the motivation for our study.

\subsubsection{Research Questions}

In this study we pose two research questions:

(i) How does material deprivation among older persons vary according to sociodemographic risk factors?

(ii) How do the relationships between material deprivation and socio-demographic risk factors vary between groups of countries with different welfare regimes?

We base our analysis on cross-sectional SHARE data, which means that the target population of our study is comprised of individuals aged 50 years and over. By using the SHARE-based MDI as opposed to the EU-SILC-based MDR, we anticipate some differences in the results compared with the studies that utilised the latter measure. In contrast to the earlier SHARE-based analyses of associations between material deprivation and socio-demographic risk factors (e.g. Adena et al. 2015; Bertoni et al. 2015; Franzese 2015), we address a wider set of risk factors and investigate the variation in their effects across welfare clusters.

\subsection{Data and Analytical Approach}

The data used in this study come from SHARE, which is a pan-European survey. It produces cross-sectional and longitudinal data on a wide range of issues related to ageing and how it affects individuals in different societal contexts, with a central focus on socio-economic circumstances, physical and mental health, living arrangements, kinship and social networks. The main advantages of SHARE are comparability across a large number of countries, representative data on older persons without imposing an upper age limit, and the relatively large sample size (BörschSupan et al. 2013).

Our analysis is based on the fifth wave of the SHARE carried out in 2013 in 15 countries-Austria, Belgium, the Czech Republic, Denmark, Estonia, France, Germany, Israel, Italy, Luxembourg, Sweden, the Netherlands, Spain, Slovenia, and Switzerland (Börsch-Supan 2018). The fifth wave included a series of questions related to material deprivation (Adena et al. 2015).

As discussed above, the SHARE-based MDI includes 11 material deprivation items that refer to the inability of households to afford basic needs and to their financial difficulties (Adena et al. 2015). The MDI was computed as the weighted sum of these failures with respect to the items described above. The MDI used in this study is based on so-called hedonic weighting, which employs the correlation between the set of deprivation items and with self-assessed satisfaction with life. The resulting 
MDI yields a score between 0 and 1 (for additional information on alternative weighting schemes and the Index, see Bertoni et al. 2015). In this study, we focus on whether individuals are materially deprived. A binary dependent variable is therefore constructed on the basis of the MDI, which is set at one if the respondent scored higher than zero on material deprivation, and zero otherwise. Our independent variables are: gender, age, living arrangements, number of children, educational attainment, labour market status, the presence of chronic diseases and activity limitations, area of residence, and migrant origin, which, based on the literature, can be expected to modulate the risk of material deprivation.

In this study our main interest relates to the variation in the relationship between material deprivation and socio-demographic risk factors across larger groups of countries, categorised as Anglo-Saxon, Continental, Nordic, Southern and Eastern European welfare regimes (e.g. Aiginger and Leoni 2009). As neither the UK nor Ireland is covered by SHARE, we omit the Anglo-Saxon welfare regime and group 15 SHARE countries into four clusters. Denmark, Sweden and the Netherlands comprise the Northern cluster. The inclusion of the Netherlands in the Northern cluster is supported by analyses of the Dutch welfare state (Sapir 2006; Eleveld and van Vliet 2013). Austria, Belgium, France, Germany, Luxembourg and Switzerland are included in the Western cluster. The Southern cluster is made up of Italy, Spain and Israel. While Israel bears some resemblance to a liberal welfare regime, the emphasis on family and religion allows the country to be included in the "extended family" of Mediterranean welfare regimes (Tarshis 2017). The Eastern cluster is comprised of the Czech Republic, Estonia, and Slovenia. Figure 3.1 presents the mean MDI values for the four clusters, which reveals marked contrasts in the levels of deprivation.

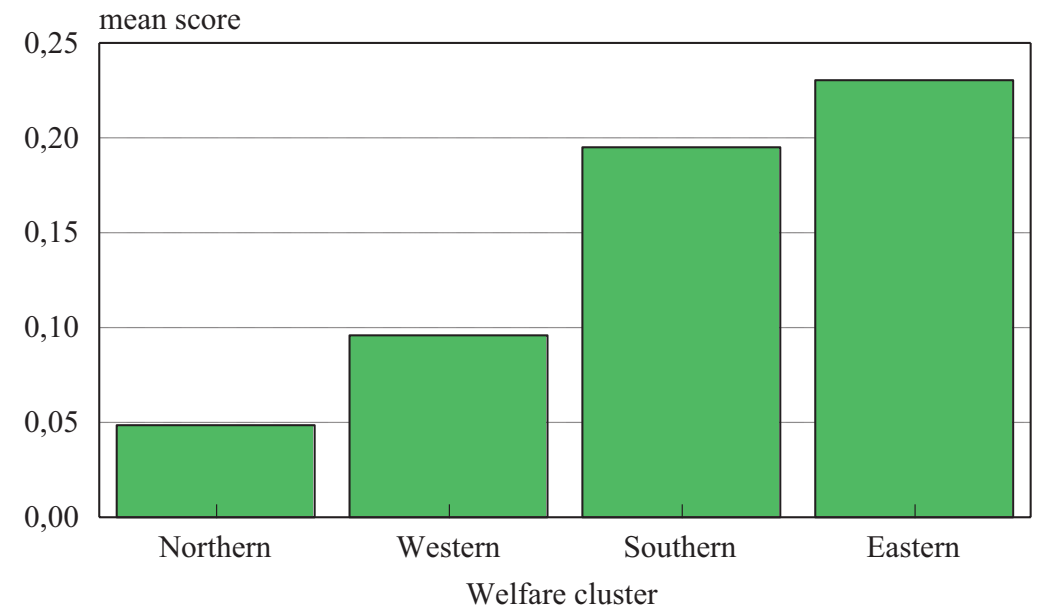

Fig. 3.1 Mean MDI score by welfare cluster, 2013

Source: SHARE database, authors' calculations 
We employ logistic regression (SPSS Version 20) to analyse the relationship between material deprivation and the risk factors. Our modelling strategy is straightforward. For each cluster of countries, we estimate a series of hierarchical models. At the exploratory stage of analysis, we also estimated models with interactions between the risk factors and the clusters of countries. As the patterns were similar, we opted for separate models. In order to produce non-adjusted estimates, we insert one independent variable at a time into the models.

The adjusted models include the full complement of independent variables. Our working sample consists of 28,578 male and 36,270 female respondents, for a total of 64,848 respondents. Table 3.1 provides information on the number of persons at different levels of the independent variables and the related percentage distributions for the clusters of countries.

\subsection{Results}

Tables 3.2, 3.3, 3.4 and 3.5 present the odds ratios from the logistic regression models. The modelling results for the different clusters for each independent variable are discussed below.

Gender In accord with previous research, the non-adjusted odds ratios reveal a moderately elevated risk of material deprivation for women in all clusters. After adjusting for the effects of the other covariates, the statistically significant female disadvantage (1.12 times) persists only in the Eastern cluster. In the Northern and Western clusters, gender makes no significant difference to the odds of material deprivation. By contrast, the Southern cluster features an inversion of the gender gradient: according to the adjusted model, women are less deprived.

Age Our results indicate considerable diversity in the age pattern of material deprivation across clusters. With regard to the non-adjusted estimates, the Northern and Western clusters exhibit no cross-cutting change in material deprivation in relation to age. The observed pattern is curvilinear with an increase in the odds ratio from 50-64 year-olds to 65-79 year-olds followed by a decrease among the 80+ age group. As a result of these opposing shifts, the non-adjusted deprivation risks among the youngest and oldest age groups are similar. By contrast, the Southern and Eastern clusters feature a systematic age-related increase in material deprivation to markedly high levels. Similar to the findings for gender, adjustment for the effects of other covariates produces a substantial transformation of the pattern. In the Northern and Western clusters, adjustment leads to the emergence of an inverse relationship between age and deprivation. Among the 80+ age group, the odds of material deprivation are 0.59 and 0.64 times lower compared with 50-64 year-olds, respectively. However, the Eastern and Southern clusters show no statistically significant association in the adjusted model between advanced age and the odds of 
Table 3.1 Descriptive statistics of socio-demographic variables used in the models, SHARE countries, 2013

\begin{tabular}{|c|c|c|c|c|c|c|c|c|}
\hline \multirow{2}{*}{ Variable } & \multicolumn{2}{|c|}{ Northern cluster } & \multicolumn{2}{|c|}{ Western cluster } & \multicolumn{2}{|c|}{ Southern cluster } & \multicolumn{2}{|c|}{ Eastern cluster } \\
\hline & Count & $\%$ & Count & $\%$ & Count & $\%$ & Count & $\%$ \\
\hline \multicolumn{9}{|l|}{ Gender } \\
\hline Male & 5836 & 46 & 10,934 & 45 & 6029 & 45 & 5779 & 41 \\
\hline Female & 6928 & 54 & 13,607 & 55 & 7348 & 55 & 8387 & 59 \\
\hline \multicolumn{9}{|l|}{ Age group } \\
\hline $50-64$ & 5507 & 44 & 11,497 & 48 & 5488 & 42 & 5830 & 42 \\
\hline $65-79$ & 5589 & 44 & 9527 & 40 & 5578 & 42 & 6328 & 45 \\
\hline $80+$ & 1504 & 12 & 3083 & 13 & 2095 & 16 & 1830 & 13 \\
\hline \multicolumn{9}{|l|}{ Living arrangements } \\
\hline Living alone & 2788 & 22 & 5686 & 23 & 1935 & 14 & 3285 & 23 \\
\hline Couple & 8223 & 64 & 13,291 & 54 & 6227 & 47 & 7160 & 51 \\
\hline Couple with others & 1462 & 11 & 4393 & 18 & 4159 & 31 & 2602 & 18 \\
\hline Single with others & 291 & 2 & 1171 & 5 & 1056 & 8 & 1119 & 8 \\
\hline \multicolumn{9}{|l|}{ Number of children } \\
\hline Childless & 1064 & 8 & 2928 & 12 & 1233 & 9 & 901 & 6 \\
\hline 1 child & 1577 & 12 & 4685 & 19 & 2283 & 17 & 2717 & 19 \\
\hline 2 children & 5370 & 42 & 9015 & 37 & 4965 & 38 & 6756 & 48 \\
\hline 3-4 children & 4033 & 32 & 6651 & 27 & 3729 & 28 & 3279 & 23 \\
\hline $5+$ children & 693 & 5 & 1212 & 5 & 925 & 7 & 485 & 3 \\
\hline \multicolumn{9}{|l|}{ Education } \\
\hline Low & 4251 & 34 & 7147 & 29 & 8952 & 68 & 4850 & 34 \\
\hline Medium & 4139 & 33 & 10,895 & 45 & 2405 & 18 & 6840 & 48 \\
\hline High & 4201 & 33 & 6262 & 26 & 1849 & 14 & 2422 & 17 \\
\hline \multicolumn{9}{|c|}{ Labour market status } \\
\hline Retired & 5841 & 46 & 12,116 & 50 & 5853 & 44 & 8467 & 60 \\
\hline Employed & 5557 & 44 & 9025 & 37 & 4254 & 32 & 4695 & 34 \\
\hline Homemaker & 515 & 4 & 2023 & 8 & 2377 & 18 & 243 & 2 \\
\hline Other & 663 & 5 & 987 & 4 & 749 & 6 & 606 & 4 \\
\hline \multicolumn{9}{|l|}{ Chronic diseases } \\
\hline $0-1$ & 7115 & 56 & 12,960 & 53 & 6813 & 51 & 6820 & 48 \\
\hline $2+$ & 5625 & 44 & 11,425 & 47 & 6526 & 49 & 7300 & 52 \\
\hline \multicolumn{9}{|l|}{ Activity limitations } \\
\hline No & 7409 & 58 & 13,554 & 55 & 8026 & 60 & 6467 & 46 \\
\hline Yes & 5333 & 42 & 10,917 & 45 & 5314 & 40 & 7660 & 54 \\
\hline \multicolumn{9}{|l|}{ Area of residence } \\
\hline Rural & 2676 & 22 & 10,164 & 42 & 2057 & 16 & 4934 & 36 \\
\hline Smaller town & 2795 & 23 & 5886 & 24 & 4177 & 33 & 3498 & 26 \\
\hline Larger town & 3065 & 25 & 2391 & 10 & 2614 & 21 & 2297 & 17 \\
\hline Suburb & 2538 & 21 & 2637 & 11 & 1198 & 10 & 817 & 6 \\
\hline City & 1264 & 10 & 2927 & 12 & 2494 & 20 & 2089 & 15 \\
\hline \multicolumn{9}{|l|}{ Origin } \\
\hline Native & 11,711 & 92 & 20,758 & 85 & 11,116 & 83 & 12,097 & 85 \\
\hline Immigrant & 1053 & 8 & 3783 & 15 & 2261 & 17 & 2069 & 15 \\
\hline
\end{tabular}

Source: SHARE database, authors' calculations 
Table 3.2 Odds ratios for material deprivation by gender and age (logistic regression models), SHARE countries, 2013

\begin{tabular}{|c|c|c|c|c|c|c|c|c|}
\hline \multirow[b]{2}{*}{ Variable } & \multicolumn{2}{|c|}{ Northern cluster } & \multicolumn{2}{|c|}{ Western cluster } & \multicolumn{2}{|c|}{ Southern cluster } & \multicolumn{2}{|c|}{ Eastern cluster } \\
\hline & $\begin{array}{l}\text { Non- } \\
\text { adjusted }\end{array}$ & Adjusted & $\begin{array}{l}\text { Non- } \\
\text { adjusted }\end{array}$ & Adjusted & $\begin{array}{l}\text { Non- } \\
\text { adjusted }\end{array}$ & Adjusted & $\begin{array}{l}\text { Non- } \\
\text { adjusted }\end{array}$ & Adjusted \\
\hline \multicolumn{9}{|l|}{ Gender } \\
\hline Male & 1 & 1 & 1 & 1 & 1 & 1 & 1 & 1 \\
\hline Female & $1.25 * * *$ & 1.07 & $1.21 * * *$ & 1.01 & $1.13 * *$ & $0.81 * * *$ & $1.23 * * *$ & $1.12 *$ \\
\hline \multicolumn{9}{|c|}{ Age group } \\
\hline $50-64$ & 1 & 1 & 1 & 1 & 1 & 1 & 1 & 1 \\
\hline $65-79$ & $0.89 * *$ & $0.79 * * *$ & $0.88 * * *$ & $0.80 * * *$ & 1.07 & $0.81 * * *$ & $1.17 * * *$ & 0.99 \\
\hline $80+$ & 1.03 & $0.59 * * *$ & 1.03 & $0.64 * * *$ & $1.54 * * *$ & 0.86 & $1.72 * * *$ & 1.07 \\
\hline
\end{tabular}

$* \mathrm{p}<0.05 ; * * \mathrm{p}<0.01 ; * * * \mathrm{p}<0.001$

Model: The dependent variable is the binary index of material deprivation. In the non-adjusted models, the independent variables were added to the model one at a time. The adjusted model includes controls for gender, age group, living arrangements, number of children, educational attainment, labour market status, chronic diseases, activity limitations, area of residence, and origin

Table 3.3 Odds ratios for material deprivation by living arrangements and number of children (logistic regression models), SHARE countries, 2013

\begin{tabular}{|c|c|c|c|c|c|c|c|c|}
\hline \multirow[b]{2}{*}{ Variable } & \multicolumn{2}{|c|}{ Northern cluster } & \multicolumn{2}{|c|}{ Western cluster } & \multicolumn{2}{|c|}{ Southern cluster } & \multicolumn{2}{|c|}{ Eastern cluster } \\
\hline & $\begin{array}{l}\text { Non- } \\
\text { adjusted }\end{array}$ & Adjusted & $\begin{array}{l}\text { Non- } \\
\text { adjusted }\end{array}$ & Adjusted & $\begin{array}{l}\text { Non- } \\
\text { adjusted }\end{array}$ & Adjusted & $\begin{array}{l}\text { Non- } \\
\text { adjusted }\end{array}$ & Adjusted \\
\hline \multicolumn{9}{|c|}{ Living arrangements } \\
\hline $\begin{array}{l}\text { Living } \\
\text { alone }\end{array}$ & 1 & 1 & 1 & 1 & 1 & 1 & 1 & 1 \\
\hline Couple & $0.43 * * *$ & $0.45 * * *$ & $0.56 * * *$ & $0.55 * * *$ & $0.65 * * *$ & $0.64 * * *$ & $0.60 * * *$ & $0.67 * * *$ \\
\hline $\begin{array}{l}\text { Couple } \\
\text { with } \\
\text { others }\end{array}$ & $0.57 * * *$ & $0.63 * * *$ & $0.67 * * *$ & $0.61 * * *$ & 1.00 & 0.98 & $0.61 * * *$ & $0.72 * * *$ \\
\hline $\begin{array}{l}\text { Single } \\
\text { with } \\
\text { others }\end{array}$ & 1.19 & 1.24 & $1.33 * * *$ & $1.17 *$ & $1.36 * * *$ & $1.23^{*}$ & 1.15 & 1.12 \\
\hline \multicolumn{9}{|c|}{ Number of children } \\
\hline Childless & $1.48 * * *$ & 1.10 & $1.15 * *$ & 0.95 & 0.90 & $0.82 *$ & $1.63 * * *$ & $1.39 * * *$ \\
\hline 1 child & $1.34 * * *$ & 1.12 & $1.21 * *$ & $1.12 * *$ & 0.93 & 0.90 & $1.44 * * *$ & $1.31 * * *$ \\
\hline 2 children & 1 & 1 & 1 & 1 & 1 & 1 & 1 & 1 \\
\hline $\begin{array}{l}3-4 \\
\text { children }\end{array}$ & $1.22 * * *$ & $1.21 * * *$ & $1.27 * * *$ & $1.27 * * *$ & $1.39 * * *$ & $1.26 * * *$ & $1.41 * * *$ & $1.38 * * *$ \\
\hline $\begin{array}{l}5+ \\
\text { children }\end{array}$ & $1.63 * * *$ & $1.45^{* * * *}$ & $2.48 * * *$ & $2.21 * * *$ & $2.80 * * *$ & $1.98 * * *$ & $2.35 * * *$ & $1.95 * * *$ \\
\hline
\end{tabular}

$* \mathrm{p}<0.05 ; * * \mathrm{p}<0.01 ; * * \mathrm{p}<0.001$

Model: The dependent variable is the binary index of material deprivation. In the non-adjusted models, the independent variables were added to the model one at a time. The adjusted model includes controls for gender, age group, living arrangements, number of children, educational attainment, labour market status, chronic diseases, activity limitations, area of residence, and origin 
Table 3.4 Odds ratios for material deprivation by education and labour market status (logistic regression models), SHARE countries, 2013

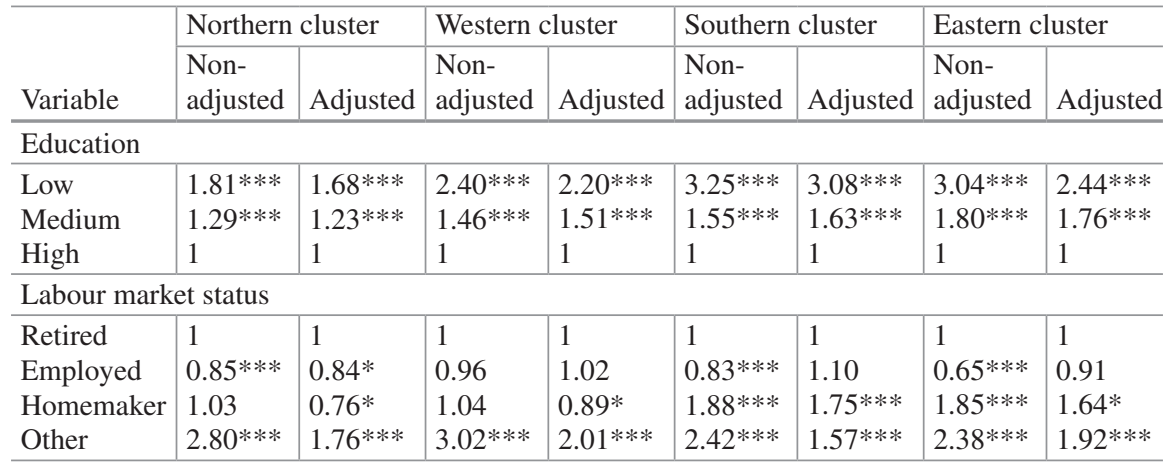

$* \mathrm{p}<0.05 ; * * \mathrm{p}<0.01 ; * * * \mathrm{p}<0.001$

Model: The dependent variable is the binary index of material deprivation. In the non-adjusted models, the independent variables were added to the model one at a time. The adjusted model includes controls for gender, age group, living arrangements, number of children, educational attainment, labour market status, chronic diseases, activity limitations, area of residence, and origin

Table 3.5 Odds ratios for material deprivation by health-related characteristics, area of residence and origin (logistic regression models), SHARE countries, 2013

\begin{tabular}{|c|c|c|c|c|c|c|c|c|}
\hline \multirow[b]{2}{*}{ Variable } & \multicolumn{2}{|c|}{ Northern cluster } & \multicolumn{2}{|c|}{ Western cluster } & \multicolumn{2}{|c|}{ Southern cluster } & \multicolumn{2}{|c|}{ Eastern cluster } \\
\hline & $\begin{array}{l}\text { Non- } \\
\text { adjusted }\end{array}$ & Adjusted & $\begin{array}{l}\text { Non- } \\
\text { adjusted }\end{array}$ & Adjusted & $\begin{array}{l}\text { Non- } \\
\text { adjusted }\end{array}$ & Adjusted & $\begin{array}{l}\text { Non- } \\
\text { adjusted }\end{array}$ & Adjusted \\
\hline \multicolumn{9}{|c|}{ Chronic diseases } \\
\hline $\begin{array}{l}0-1 \\
2+\end{array}$ & $\begin{array}{l}1 \\
1.39 * * *\end{array}$ & $\begin{array}{l}1 \\
1.12 * * *\end{array}$ & $\begin{array}{l}1 \\
1.43 * * *\end{array}$ & $\begin{array}{l}1 \\
1.18 * * *\end{array}$ & $\begin{array}{l}1 \\
1.88 * * *\end{array}$ & $\begin{array}{l}1 \\
1.40 * * *\end{array}$ & $\begin{array}{l}1 \\
1.59 * * *\end{array}$ & $\begin{array}{l}1 \\
1.07\end{array}$ \\
\hline
\end{tabular}

Activity limitations

\begin{tabular}{|c|c|c|c|c|c|c|c|c|}
\hline $\begin{array}{l}\text { No } \\
\text { Yes }\end{array}$ & $\begin{array}{l}1 \\
1.70 * * *\end{array}$ & $\begin{array}{l}1 \\
1.49 * * *\end{array}$ & $\begin{array}{l}1 \\
1.84 * * *\end{array}$ & $\begin{array}{l}1 \\
1.62 * * *\end{array}$ & $\begin{array}{l}1 \\
2.53 * * *\end{array}$ & $\begin{array}{l}1 \\
2.08 * * *\end{array}$ & $\begin{array}{l}1 \\
2.33^{* * * *}\end{array}$ & $\begin{array}{l}1 \\
1.92 * * *\end{array}$ \\
\hline \multicolumn{9}{|c|}{ Area of residence } \\
\hline $\begin{array}{l}\text { Rural } \\
\text { City } \\
\text { Suburb } \\
\text { Larger } \\
\text { town } \\
\text { Smaller } \\
\text { town }\end{array}$ & $\begin{array}{l}1 \\
0.94 \\
1.10 \\
0.96 \\
1.01\end{array}$ & $\begin{array}{l}1 \\
0.91 \\
1.06 \\
0.92 \\
0.99\end{array}$ & $\begin{array}{l}1 \\
0.99 \\
0.93 \\
1.11^{*} \\
1.00\end{array}$ & $\begin{array}{l}1 \\
0.98 \\
0.91 \\
1.04 \\
1.00\end{array}$ & $\begin{array}{l}1 \\
0.63 * * * \\
0.96 \\
0.93 \\
0.84\end{array}$ & $\begin{array}{l}1 \\
0.73 * * * \\
1.12 \\
1.07 \\
0.90\end{array}$ & $\begin{array}{l}1 \\
0.77 * * * \\
0.53 * * * \\
0.92 \\
0.90\end{array}$ & $\begin{array}{l}1 \\
0.82 * \\
0.57 * * * \\
0.86^{*} \\
0.94\end{array}$ \\
\hline \multicolumn{9}{|l|}{ Origin } \\
\hline $\begin{array}{l}\text { Native } \\
\text { Immigrant }\end{array}$ & $\begin{array}{l}1 \\
1.80^{* * * *}\end{array}$ & $\begin{array}{l}1 \\
1.62 * * *\end{array}$ & $\begin{array}{l}1 \\
1.66 \text { *** }\end{array}$ & $\begin{array}{l}1 \\
1.62 * * *\end{array}$ & $\begin{array}{l}1 \\
0.94\end{array}$ & $\begin{array}{l}1 \\
1.38 * * *\end{array}$ & $\begin{array}{l}1 \\
2.31 * * *\end{array}$ & $\begin{array}{l}1 \\
2.44 * * *\end{array}$ \\
\hline
\end{tabular}

$* \mathrm{p}<0.05 ; * * \mathrm{p}<0.01 ; * * \mathrm{p}<0.001$

Model: The dependent variable is the binary index of material deprivation. In the non-adjusted models, the independent variables were added to the model one at a time. The adjusted model includes controls for gender, age group, living arrangements, number of children, educational attainment, labour market status, chronic diseases, activity limitations, area of residence, and origin 
deprivation. Among the 65-79 age group, differences across welfare clusters are smaller.

Living Arrangements The association between household context and material deprivation is strong and relatively uniform. In all clusters, living as a couple markedly reduces the odds of deprivation relative to living alone. In the adjusted model, the reduction appears largest in the Northern cluster ( 0.45 times) and smallest in the Eastern cluster ( 0.67 times). Interestingly, the contrast between living as a couple and living alone peaks in the Northern cluster. Considering that the welfare systems in the Nordic countries are the least familistic, one might have expected a different result.

In most clusters, couples living with others are also better protected against material deprivation than older individuals living alone. The only exception is the Southern cluster in which the presence of other family members in the household is associated with the same risk of material deprivation as experienced by those living in one-person households. Finally, the highest odds of material deprivation are found among single persons living with others. In the Western and Southern clusters, their risk of deprivation significantly exceeds that of the reference group. The similarity of the adjusted and non-adjusted estimates suggests that the relationship between living arrangements and material deprivation is relatively independent of the other factors considered in the analysis.

Number of Children In most clusters, childlessness and having one child are associated with elevated risks of material deprivation relative to the reference group (individuals with two children) in the non-adjusted models. However, after adjustment, moderate excess risks persist only in the Eastern cluster, and to a limited extent in the Western cluster (only for those with one child). In the Southern cluster, childlessness is associated with lower odds of deprivation. However, having a large family distinctly increases the risks of material deprivation in all clusters. In the Western, Southern and Eastern clusters having five or more children is associated with a 1.95 to 2.21 increase in the adjusted odds of deprivation. Only in the Northern cluster does the excess risk appear somewhat smaller, plausibly reflecting the capability of Nordic welfare systems to bolster economic inequalities arising from family circumstances.

Education In all clusters, individuals with a medium or low education exhibit substantially higher risks of deprivation compared with those with high education. In the adjusted models, the odds ratio of deprivation ranges from 1.23 to 1.76 for medium-educated older persons, and from 1.68 to 3.04 for those with low education. Plausibly supported by generous welfare systems and lower economic inequality, differences in material deprivation according to the level of education appear smallest in the Northern cluster. By contrast, the largest differences are found in the Southern and Eastern clusters. 
Labour Market Status The non-adjusted estimates show that being employed reduces the risk of material deprivation: with the exception of the Western cluster, the difference from the reference group (retirees) is statistically significant. However, after adjustment for the effects of the other covariates, the protective effect associated with employment loses significance in most clusters. This suggests that retirement in itself does not involve a significant increase in the risks of material deprivation. The opposite may hold true in the Northern cluster, although only to a limited extent.

The association between homemaking and material deprivation exhibits more variation. In the Northern and Western clusters, homemakers do not show any excess risk of deprivation. According to the adjusted estimates, the odds of being deprived are as much as 0.76 times lower for homemakers relative to the reference group. In the Eastern and Southern clusters, however, homemaking is related to a significant excess in risk of deprivation, ranging from 1.64 to 1.75 . Individuals in the residual category feature substantially elevated risks of material deprivation, but, unlike for homemakers, the pattern is similar across clusters.

Chronic Diseases and Activity Limitations Having multiple chronic diseases and activity limitations adds substantially to the risk of deprivation. In all clusters but one (the Eastern), a significant association between deprivation and chronic diseases persists after the inclusion of the other covariates in the model. The effects of activity limitations are significant in all clusters. The effect appears more pronounced in Southern and Eastern clusters and more moderate in Northern and Western clusters. This suggests that welfare systems in the Northern and Western clusters are more supportive of the economic needs of older persons in poor health.

Area of Residence Area of residence makes only a limited difference in the risks of material deprivation. In the Northern and Western clusters, differences in the odds of deprivation associated with area of residence are not significant. In the Southern cluster, living in a city entails a reduction of 0.73 times in the odds of deprivation relative to rural residence. In the Eastern cluster, the largest advantage relates to living in suburbs. This finding is not surprising, as many countries of Eastern Europe experienced a tide of suburbanisation among the more affluent strata of the population after the fall of state socialism. Overall, in both the Southern and Eastern clusters, the results indicate a disadvantage for rural residents that is not counterbalanced by the welfare system [see Vidovićová et al. this volume for the consequences of such a disadvantage for care provision].

Origin Although arrival in the host country usually occurs relatively early in the life course, the disadvantage associated with immigrant origin does not disappear but persists well into old-age. Our results show that higher risks of deprivation among immigrants can be found in all clusters. However, there is a considerable variation in the odds ratios of deprivation for immigrants, ranging from 1.38 in the Southern cluster to 2.44 in the Eastern cluster in the adjusted model. We think that 
the observed differences stem not only from contrasts between host societies but also from the diverse origins and characteristics of immigrants across clusters.

\subsection{Conclusion}

In this chapter, we used SHARE data to investigate the risk of material deprivation of older persons as a dimension of economic exclusion associated with sociodemographic factors in 14 countries across Europe and Israel. In the context of research on material deprivation, the contribution of our study is derived from several elements. First of all, the SHARE material deprivation index employed in this study is specifically designed to consider the material needs of older persons (Adena et al. 2015). Furthermore, only a few comparative analyses of material deprivation have been conducted on the basis of SHARE data (Bertoni et al. 2015; Franzese 2015; Hunkler et al. 2015). However, to the best of our knowledge, none of the SHARE-based analyses have systematically investigated the variation in the role of socio-demographic risk factors across country clusters with different welfare regimes in contemporary Europe. An extended range of risk factors pertaining to individuals rather than the head of household also enhances its contribution to the literature. Finally, the strict harmonisation of the SHARE data circumvents the lack of comparability that plagues the findings from single-country studies.

The study found statistically significant effects for all the risk factors considered. In accordance with most previous research (Boarini and Mira d'Ercole 2006; Bárcena-Martin et al. 2014), lower education, living alone, having health-related activity limitations, and being of immigrant origin markedly elevated the risk of material deprivation among older persons, sometimes doubling the odds. For gender, age, and area of residence, the effects were less pronounced. Corroborating earlier comparative studies of the older population (Jehoel-Gijsbergs and Vrooman 2008; Bertoni et al. 2015), our findings suggest that older persons in the countries of Northern and Western Europe are generally less materially deprived than their counterparts in Southern and Eastern Europe. This indicates that the welfare regimes may play a protective role buffering against material deprivation in later life.

Separate models for clusters of countries revealed some interesting and seldom reported variations in the effects associated with the risk factors. Although most earlier studies have found that women are more deprived than men (Muffles and Fouarge 2004; Bertoni et al. 2015), in this study this was found to be true, and only to a limited extent, in the Eastern cluster. For other groups of countries women exhibited similar (Northern and Western) or even lower (the Southern cluster) risks of deprivation than men. A commonly reported pattern whereby deprivation risks decrease with age (Jehoel-Gijsbergs and Vrooman 2008) was observed only in the Northern and Western clusters; in other clusters the risks did not diminish or did so for only part of the older population. While previous research has focussed on the relationship between the number of children currently living in the household (Boarini and Mira d'Ercole 2006), our study provides insight into the effects 
associated with the number of offspring irrespective of co-residence with their parents. The results suggest that the disadvantage related to having a large family persists well into old-age in all clusters. Finally, there are also differences between clusters associated with the effects of homemaking, area of residence, and migrant status that have not been reported in previous studies. This suggests that material deprivation does not always affect vulnerable groups to the same degree in all countries.

Across clusters of countries, the smallest differences in deprivation risks associated with socio-demographic factors are characteristic of the Northern cluster. The results for the Western cluster appear quite similar. By contrast, the Southern and Eastern clusters exhibit much larger differences in the risks of material deprivation. A closer examination of the results suggests that the Eastern cluster more frequently ranks higher than the Southern cluster [see Grigoryeva et al. this volume for a discussion of welfare reform in Eastern and post-Soviet contexts]. These findings lend support to the notion that more generous welfare systems and greater equality provide better support to population groups at risk of material deprivation. With regard to policy implications that are relevant for economic exclusion, this study identifies subgroups of the older population that encounter disproportionately high risks of material deprivation, in some or all clusters, that will need consideration into the future as ageing populations grow and become increasingly diverse.

\section{Editors' Postscript}

Please note, like other contributions to this book, this chapter was written before the COVID-19 pandemic of 2020. The book's introductory chapter (Chap. 1) and conclusion (Chap. 34) consider some of the key ways in which the pandemic relates to issues concerning social exclusion and ageing.

Acknowledgements This study was supported by a grant from the Estonian Research Council (PRG71). The study uses data from SHARE wave 5 (DOI:https://doi.org/10.6103/SHARE. w5.700).

\section{References}

Adena, M., Myck, M., \& Oczkowska, M. (2015). Material deprivation items in SHARE wave 5 data: A contribution to a better understanding of differences in material conditions in later life. In A. Börsch-Supan, T. Kneip, H. Litwin, M. Myck, \& G. Weber (Eds.), Ageing in Europe Supporting policies for an inclusive society (pp. 25-37). Berlin: De Gruyter.

Aiginger, K., \& Leoni, T. (2009). Typologies of social models in Europe. Vienna: Austrian Institute of Economic Research WIFO.

Bárcena-Martín, E., Lacomba, B., Moro-Egido, A. I., \& Pérez-Moreno, S. (2014). Country differences in material deprivation in Europe. Review of Income and Wealth, 60(4), 802-820. 
Bertoni, M., Cavapozzi, D., Celidoni, M., \& Trevisan, E. (2015). Assessing the material deprivation of older Europeans. In A. Börsch-Supan, T. Kneip, H. Litwin, et al. (Eds.), Ageing in Europe - Supporting policies for an inclusive society (pp. 49-56). Berlin: De Gruyter.

Boarini, R., \& Mira d'Ercole, M. (2006). Measures of material deprivation in OECD countries (OECD Social, Employment And Migration Working Papers No. 37). Paris: OECD.

Börsch-Supan, A. (2018). Survey of health, ageing and retirement in Europe (SHARE) Wave 5. Release version: 6.1.0. SHARE-ERIC. Data set.

Börsch-Supan, A., Brandt, M., Hunkler, C., Kneip, T., Korbmacher, J., Malter, F., et al. (2013). Data resource profile: The survey of health, ageing and retirement in Europe (SHARE). International Journal of Epidemiology, 42(4), 992-1001.

De Graaf-Zijl, M., \& Nolan, B. (2011). Household joblessness and its impact on poverty and deprivation in Europe. Journal of European Social Policy, 21(5), 413-431.

Dewilde, C. (2008). Individual and institutional determinants of multidimensional poverty: A European comparison. Social Indicators Research, 68(2), 233-256.

Eleveld, A., \& van Vliet, O. (2013). The Dutch welfare state: Recent reforms in social security and labour law. Diritto Pubblico Comparato Ed Europeo, 4, 1371-1399.

Eurostat. (2019). EU statistics on income and living conditions (EU-SILC) methodology. https:// ec.europa.eu/eurostat/statistics-explained/index.php/EU_statistics_on_income_and_living_ conditions_(EU-SILC)_methodology. Accessed 3 Dec 2019.

Franzese, F. (2015). Slipping into poverty: Effects on mental and physical health. In A. BörschSupan, T. Kneip, H. Litwin, M. Myck, \& G. Weber (Eds.), Ageing in Europe - Supporting policies for an inclusive society (pp. 139-147). Berlin: De Gruyter.

Fusco, A., Guio, A.-C., \& Marlier, E. (2010). Characterising the income poor and the materially deprived in European countries. In A. B. Atkinson \& E. Marlier (Eds.), Income and living conditions in Europe (Eurostat statistical books). Luxembourg: Publications Office of the European Union.

Fusco, A., Guio, A.-C., \& Marlier, E. (2013). Building a material deprivation index in a multinational context: Lessons from the EU experience. In V. Bérenger \& F. Bresson (Eds.), Poverty and social exclusion around the Mediterranean Sea (Economic studies in inequality, social exclusion and well-being 9) (pp. 43-71). New York: Springer.

Guio, A.-C. (2009). What can be learned from deprivation indicators in Europe? (Eurostat Methodologies and Working Paper). Eurostat: Luxembourg.

Hrast, M. F., Mrak, A. K., \& Rakar, T. (2013). Social exclusion of elderly in Central and Eastern Europe. International Journal of Social Economics, 40(11), 971-989.

Hunkler, C., Kneip, T., Sand, G., \& Schuth, M. (2015). Growing old abroad: Social and material deprivation among first-and second generation migrants in Europe. In A. Börsch-Supan, T. Kneip, H. Litwin, M. Myck, \& G. Weber (Eds.), Ageing in Europe-supporting policies for an inclusive society (pp. 199-208). Berlin: De Gruyter.

Jehoel-Gijsbers, G., \& Vrooman, C. (2008). Social exclusion of the elderly: A comparative study of EU member states (ENEPRI research report no. 57). Brussels: ENEPRI.

Levasseur, M., Cohen, A. A., Dubois, M. F., Généreux, M., Richard, L., Therrien, F. H., \& Payette, H. (2015). Environmental factors associated with social participation of older adults living in metropolitan, urban, and rural areas: The NuAge study. American Journal of Public Health, 105(8), 1718-1725.

Muffels, R., \& Fouarge, D. (2004). The role of European welfare states in explaining resources deprivation. Social Indicators Research, 68(3), 299-330.

Myck, M., Ogg, J., Aigner-Walder, B., Kåreholt, I., Kostakis, I., Motel-Klingebiel, A., et al. (2017). Economic aspects of old age exclusion: A scoping report. ROSEnet Economic Working Group, Knowledge synthesis series: No. 1. CA 15122 Reducing Old-Age Exclusion: Collaborations in Research and Policy.

Nelson, K. (2012). Counteracting material deprivation: The role of social assistance in Europe. Journal of European Social Policy, 22(2), 148-163.

Renahy, E., Alvarado-Llano, B., Koh, M., \& Quesnel-Vallée, A. (2012). Income and economic exclusion: Do they measure the same concept? International Journal for Equity in Health, 11, 4. https://doi.org/10.1186/1475-9276-11-4. 
Saltkjel, T., \& Malmberg-Heimonen, I. (2017). Welfare generosity in Europe: A multi-level study of material deprivation and income poverty among disadvantaged groups. Social Policy and Administration, 51(7), 1287-1310.

Sapir, A. (2006). Globalization and the reform of European social models. Journal of Common Market Studies, 44(2), 369-390.

Saunders, P. (2008). Social exclusion: Challenges for research and implications for policy. The Economic and Labour Relations Review, 19(1), 73-92.

Scharf, T. (2015). Between inclusion and exclusion in later life. In K. Walsh, G. Carney, \& Á. N. Léime (Eds.), Ageing through austerity: Critical perspectives from Ireland (pp. 113-130). Bristol: Policy Press.

Scharf, T., Phillipson, C., \& Smith, A. E. (2005). Social exclusion of older people in deprived urban communities of England. European Journal of Ageing, 2(2), 76-87.

Tarshis, N. (2017). Israel as a welfare state: A visual essay. Bulletin Articles. http://taubcenter.org. il/israel-as-a-welfare-state/. Accessed 12 Sept 2019.

Walsh, K., Scharf, T., \& Keating, N. (2017). Social exclusion of older persons: A scoping review and conceptual framework. European Journal of Ageing, 14(1), 81-98.

Open Access This chapter is licensed under the terms of the Creative Commons Attribution 4.0 International License (http://creativecommons.org/licenses/by/4.0/), which permits use, sharing, adaptation, distribution and reproduction in any medium or format, as long as you give appropriate credit to the original author(s) and the source, provide a link to the Creative Commons license and indicate if changes were made.

The images or other third party material in this chapter are included in the chapter's Creative Commons license, unless indicated otherwise in a credit line to the material. If material is not included in the chapter's Creative Commons license and your intended use is not permitted by statutory regulation or exceeds the permitted use, you will need to obtain permission directly from the copyright holder. 